\title{
PLOUGHING IN RESOURCES
}

\section{The investigation of farm attacks}

Duxita Mistry, Institute for Security Studies

duxita@iss.co.za

The information contained in this article is drawn primarily from research conducted by the Committee of Inquiry into Farm Attacks. The mandate of this Committee was to investigate the motive for farm attacks. To this end the Committee interviewed investigating officers, victims, offenders and prosecutors. In addition, the agricultural unions, the South African Police Service, non-governmental organisations and the South African National Defence Force made submissions to the Committee. The Committee found that the primary motive for farm attacks was robbery and, more importantly, that the conviction rate was high at $90 \%$. This article therefore examines the investigative techniques used in the investigation of farm attacks and suggests that the little known Tracking Unit is a significant factor in the successes achieved to date. Its past experience in dealing with politically motivated insurgency in rural areas has proven effective in apprehending suspects. However, these techniques have not been effective in reducing the number of attacks. This article explores how farm attack cases have been handled by the criminal justice system.

\section{Background}

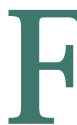
arm attacks ${ }^{1}$ appear to be a phenomenon unique to South Africa. Although crimes such as murder, robbery with aggravating circumstances and rape do occur on commercial farms elsewhere in the world, these have been singled out for special attention in South Africa due to the sensitivity and the scale of the issue (see Figure 1 on page 11). Farm attacks have been accorded the status of a 'priority crime'. This means that organised agriculture, representatives of the South African N ational D efence Force (SANDF) and the South African Police Service (SAPS) meet regularly to plan, co-ordinate, execute and integrate strategies to reduce the incidence of farm attacks.

In an attempt to understand farm attacks, focus group interviews and one-on-one interviews were undertaken with investigating officers and perpetrators respectively. ${ }^{2}$ Focus group interviews were conducted with investigating officers in all nine provinces. Investigators estimated that the conviction rate for farm attacks ranged from $50 \%$ to $90 \%$ - much higher than for other violent crimes. However, the Committee was unable to verify these figures with statistics from the Crime Information Analysis Centre (CIAC). Given the sparse, isolated areas in which farm attacks are carried out one would assume that the conviction rate for farm attacks would be low, because victims are far from a police station and perpetrators have enough places to hide.

In an attempt to determine the relative conviction rate for similar crimes in an urban area the Committee relied on the CIAC in the Eastern Cape for assistance. ${ }^{3}$ The Committee requested the CIAC to carry out a comparison between house robberies 
on farms and urban areas. Due to the availability of data and a belief that provincial trends would probably reflect national trends, the Committee used the Eastern Cape data. The data covered the two-year period 2000 and 2001. In sum, the exercise revealed that in $43 \%$ of house robberies on farms there had been a conviction but by contrast there was only a $6 \%$ conviction rate in the urban areas. ${ }^{4} \mathrm{~A}$ further $53 \%$ of cases on farms were either undetected or withdrawn and $4 \%$ ended with an acquittal. By contrast, $92 \%$ of cases in the urban areas were undetected or withdrawn and $2 \%$ were acquittals.

The question that should be asked: why is the arrest and conviction rate for farm attacks so high? Supporting this Eastern Cape trend, investigators in the focus groups were of the opinion that only a small number of cases remained unsolved.

Moreover, the sentences handed down to perpetrators were rather stiff. Research carried out by Mistry and Dhlamini found that the sentences handed down to perpetrators ranged from 10 years for common robbery to 25 years for murder, possession of illegal weapons and ammunition. ${ }^{5}$ According to the judgements handed down, none of these sentences were reviewable. In the beginning, the conviction rate for farm attacks may have been low but the figure has increased to $90 \%$ in some areas. $^{6}$ The high success rate can be attributed to three factors:

- Political will;

- Resources; and

- Investigation techniques.

Each of these factors will be discussed in more detail in the following sections.

\section{The political will}

O rganised agriculture garnered a great deal of support from white commercial farmers and prevailed upon government to take responsibility for the safety and security of farmers. Consequently, in O ctober 1998 former President M andela hosted a Rural Safety Summit to address the concerns of organised agriculture. O rganised agriculture was of the opinion that the criminal justice system was ineffective and that perpetrators of farm attacks were, literally, getting away with murder. In addition, organised agriculture was also of the opinion that the attacks on white commercial farmers were politically and racially motivated - the idea being to drive white people off the farms in order to make land available for redistribution. By typifying the attacks in such a way, the agricultural unions contributed to the popular perception that farm attacks were a continuation of the armed struggle against the apartheid state waged by U mkhonto weSizwe (MK) and APLA. A definition of farm attacks was drawn up (see endnote 1 ) as a result of lobbying by organised agriculture, and in 1998 it was given the status of a priority crime.

$O$ ther priority crimes include crimes against women and children, gang and taxi violence, and bankrelated crimes. The Rural Protection Plan (RPP) was devised in response to representations to the National O perational Co-ordinating Committee $(\mathrm{NOCOC})^{7}$ by organised agriculture. O nce farm attacks were given the status of a priority crime, a subcommittee on Rural Safety was formed. This is a subcommittee of NOCOC. ${ }^{8}$ The priority committee on Rural Safety consists of members of the SAPS including the Crime Information Analysis Centre $(C I A C)$, members of the SANDF, organised agriculture in the form of AgriSA, and the Department of Land Affairs (DLA). This committee meets every Thursday to discuss the reports of farm attacks received from the various CIAC offices throughout the country. The members of the committee examine each incident to determine whether or not a particular incident can be classified as a farm attack.

The priority committee on Rural Safety is tasked with the operational planning and implementation of the RPP. ${ }^{9} \mathrm{O}$ ther functions include:

- Co-ordinating all security-related actions relating to rural protection;

- Identifying factors that have a negative influence on the safety of the farming community; and

- Distributing relevant information and providing feedback on the rural protection plan to all relevant role players. ${ }^{10}$

Prioritising a crime may be the most effective way of demonstrating political will, but in order to combat farm attacks the following resources need to 
be mobilised and utilised:

- Commandos

- Tracking Unit

- Air wing, Disaster M anagement Team

At least two of the mechanisms mentioned above are legacies of the past. The commandos were established in response to guerrilla infiltration, and MK and APLA attacks on farms. As a result of the political transition, these commandos fell into disuse. However, with the increasing incidence of farm attacks, the commandos were given a new lease of life and legitimacy. Similarly, members of the Tracking Unit served with the SADF in the bush war. This will be discussed in more detail below. The marnet radio system, ${ }^{11}$ which appears to be widely used in rural areas, is yet another example of old war techniques. All these instruments come from the apartheid state's response to rural insurgency in the 1980s.

\section{Investigation techniques}

D ue to their status as priority crimes, farm attacks are generally investigated by a specialised unit, the Serious and Violent Crime U nit. The members of this unit are well-trained, seasoned investigators.

The investigators interviewed said that they applied the same techniques to farm attacks as they do to other similar crimes. None of them have, however, received any special training in respect of farm attacks. Their expertise has been gleaned from the number of farm attacks investigated over the last few years. The investigators are divided into field teams. This ensures that each investigator is utilised to the best of his or her ability. Investigators and station level detectives work together because the latter are knowledgeable about local systems and informants. In order to optimise prosecution rates the most experienced investigator is sent to court to give evidence. This ensures that the case is presented in a professional manner by an articulate investigator. The investigators work closely with the prosecutors.

The investigators revealed that they are very committed to their work and some are even known to sleep at the crime scene or work throughout the night on apprehending the suspects. This is unlikely to be the practice in urban areas. The use of the informer network is also a valuable source of information in all investigations. In some areas the investigators give priority to an incident on a farm at the expense of other cases. In others, the investigators are able to work equally well on violent crimes in urban and rural areas. Once the police have been notified of a farm attack, the forensics experts, Tracking U nit and investigators rush to the crime scene. The forensic experts collect evidence and the Tracking U nit is able to determine how the suspects entered the homestead. In addition, in examining how the victims were attacked the forensic experts ascertain what instruments or weapons were used. This information points to the type of suspects the investigators should be looking for.

\section{Tracking U nit}

This unit is one of the most effective and invaluable tools at the disposal of the SAPS in farm attack investigations. It makes a major contribution to the arrests of suspects and subsequent convictions. The Tracking U nit is used for tracking, pursuing and arresting suspects. It also determines how the suspects entered the homestead and for what purpose. These units typically have a few members from $\mathrm{O}$ vamboland in Namibia who are internationally considered among the foremost experts in tracking. They were used widely by the former South African Defence Force to track down SWAPO guerrillas in the bush war.

Even though there are courses for trackers in South Africa, the farm investigators regard these members of the Tracking U nit as the very best. A member of the Tracking $U$ nit stated that his members are able to follow the track (spoor) of the suspects longer than are the dog units. Moreover, they are also able to find clues regarding the age of the tracks and the condition of the suspects. For example, they are able to see minute bloodstains in the sand and assess the freshness of the tracks. In addition, the height, weight, speed and fitness of the suspect can be determined from his tracks. In this manner the Tracking U nit also assists the air wing of the SAPS in its search for the suspects.

From 1998 to 2001 most farm attacks occurred in Gauteng, Mpumalanga, KwaZulu-Natal and the 
N orth West respectively. The Tracking U nits are located in three provinces, the Eastern Cape, Free State and Limpopo: large, sparsely populated rural areas. The Tracking U nit in Limpopo Province has the most members, while the Eastern Cape unit only has three. But as these provinces in fact do not account for the highest number of farm attacks, the question must be asked whether this can be attributed to the existence of the Tracking U nits.

\section{Commandos}

The effectiveness of the commandos varies from one area to the next. The commandos are tasked with assisting the police with rural safety and security. The commando is often made up of local farmers who may or may not be former members of the SANDF. They are issued with state weapons. These commandos are often the first to receive a call for assistance from the farmer under attack, since farms are generally far away from police stations. Many farmers in the rural areas are linked to each other via a marnet radio system. The commandos then call the police and inform them that a crime has been committed. They set up a roadblock and start looking for the suspects.

There are three types of commando structures in the rural areas:

- Area-bound reaction force commando members

- Home and Hearth protection reaction force commando members, and

- House and Hearth protection commando members. ${ }^{12}$

Area-bound reaction force units are composed of people who live in towns and cities. ${ }^{13}$ When there is an emergency these members are called upon to assist, and are issued with a uniform and rifle for that purpose. The members of this unit are trained with police reservists to conduct patrols, roadblocks, follow-up operations, cordon and search operations, and farm visits. ${ }^{14}$

Home and Hearth protection reaction force commando members are made up of farmers, smallholders, and their labourers. O nce an incident has been reported on a farm in the area this commando is called. They set up roadblocks and a search begins for the suspects. House and Hearth protection commando members are composed in the same manner as the Home and Hearth protection reaction force commandos. However, they only protect their own properties and are given a rifle if they do not have their own. In addition to relying on the commandos, a contingency plan has been drawn up in some areas, using members of the local community to assist the police. This also contributes to the high rate of successful farm investigations.

In the Bushveld area of Limpopo, as well as in the Eastern Cape, contingency plans have been drawn up to determine what should be done at the scene of a farm attack. The Area Co-ordinating Committee (AOCOC) oversees these plans. In sum, a Joint $O$ perations Centre $(\mathrm{JOC})$ is set up, and the investigation of a farm attack is co-ordinated from this spot. Any information emanating from the crime must be relayed to the $\mathrm{JOC}$, who then sends it on to the relevant stakeholders. In the Bushveld area, in addition to mobilising the Tracking U nit, commandos and air wing, a disaster management team is also called upon to assist. Each of the stakeholders has a clearly defined role in the contingency plan. Hence, there is no confusion when the plan is put into action, and valuable time is not lost. The plan also states who will be in command of the investigation.

On the 14th of February 2003 President M beki announced that the commando system would be phased out and replaced with sector policing under the leadership of the SAPS. The reasoning behind this was that crime prevention was not the mandate of the SANDF, but the responsibility of the SAPS. ${ }^{15}$ The President's announcement created a great deal of unhappiness amongst farmers who rely upon commandos for rural safety and security. $0 n$ the 5 th of August 2003 the minister of Safety and Security confirmed that the commandos would be phased out over six years, but that special police units would be established in the rural areas and that commando members could get involved in these.

\section{Air wing}

The air wing of the SAPS, using light aircraft, is often called upon to support and assist the Tracking $U$ nit in its search for suspects. The Tracking U nit 
relays vital information to the air wing, for instance about the height and build of the suspects.

\section{Limitations to the strategy}

As discussed, the three factors that have contributed to the high conviction rates for farm attacks are political will, investigation techniques, and resources. It is clear that a great deal has been invested in the investigation of farm attacks, yet these crimes continue to increase. Figure 1 below shows the number of farm attacks recorded by the police since $1997 .{ }^{16}$

Figure 1: Number of farm attacks 97-02

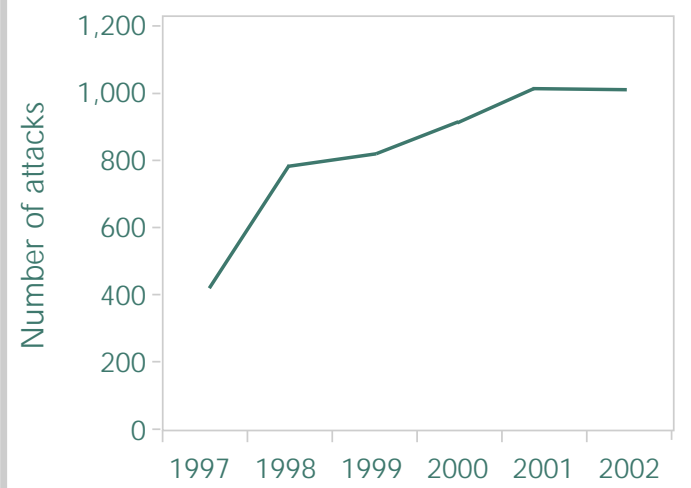

It would appear that old techniques from the guerrilla war have been applied in dealing with farm attacks. This strategy has resulted in high conviction rates but not in a reduction in the incidence of farm attacks.

Firstly, the problem lies with the reactive nature of policing farm attacks. M ost of the infrastructure is geared to the aftermath of farm attacks and not to prevention. Secondly, even though the tracking units in the Free State and Eastern Cape play a major role in the success of investigations into farm attacks, they are small entities attempting to cover vast areas. Ideally, there should be tracking units in each area, attached to a serious and violent crimes unit.

In addition, the SAPS have not actively recruited members to the Tracking U nits. Consequently, their unique tracking skills appear to be dying out.
Training courses are held at U pington in the N orthern Cape, rather than in the areas in which the members are based. It is important for the Tracking U nit members to be trained in the areas in which they are based as each unit is dealing with different terrain. It is also necessary to regularly update the course. Moreover, members of the various Tracking Units should be brought together to share expertise and experiences.

W hat is needed to complement the current strategies is a comprehensive proactive intervention strategy. Part of the solution falls within the domain of security on farms. Research carried out by Mistry and D hlamini amongst perpetrators of farm attacks and in interviews with investigators revealed that security measures on some farms leave a lot to be desired. ${ }^{17} \mathrm{M}$ any farmhouses have no burglar bars on their windows or security gates on their doors. W indows and doors are often left open, and in some cases there is no fence around the homestead.

\section{Concluding remarks}

Sector policing is being touted as a potential solution to the reduction in incidents of farm attacks. This would increase the visibility of the police in rural areas that are usually isolated and vulnerable to crime. How ever, a good communication strategy is required. The police need to ensure that they have a regular slot on local radio stations in which they convey information on any incidents, suspects wanted, whether or not suspects have been arrested and the sentences handed down to perpetrators. This may help to reduce the incidence of crime on farms, as is the case in the Bushveld area of Limpopo Province.

Another important factor to consider is the role played by farm workers. They are an integral part of rural communities and there are known cases where they have been used unwittingly by perpetrators to obtain information about certain farms. Research undertaken by the Committee found that farm workers are secondary victims of farm attacks, and although they may escape harm, are most likely to suffer when farms are sold, downsized or liquidated. None of the commandos have integrated farm workers into their structures. However, farm workers have a stake in the 
apprehending of perpetrators and may well be willing to participate in rural safety and security structures. As such, they are a significant resource in terms of any rural safety plan and need to be recruited more actively in this regard.

Although the large number of farm attacks has been dwarfed by the number of violent crimes committed in urban areas, the prioritisation of farm attacks means that victims are more likely to see an arrest, and the prosecution and conviction of a perpetrator. However, this may appear to be inequitable. In the context of severely limited resources, any disproportional allocation of resources to tackle any one type of crime (no matter how politically sensitive) can only be at the expense of other needs. In the long run, addressing farm attacks depends on justice not only being done to farm attackers but on justice being done and being seen to be done with respect to criminal behaviour at large - and this within the context of less social and economic injustice.

\section{Endnotes}

1 Attacks on farms and smallholdings refer to acts aimed at the person(s) of residents, workers and visitors to farms and smallholdings, whether with the intent to murder, rape, rob or to inflict bodily harm. In addition, all actions aimed at (disrupting) farming activities as a commercial concern, whether for motives related to ideology, labour disputes, land issues, revenge, grievances, racist concerns or intimidation, should be included. (Cases related to domestic violence or drunkenness, or resulting from commonplace social interaction between people - often where victims and offenders are known to one another - are excluded from this definition).

2 Nine focus group interviews, one in each province with investigating officers. On average there were between 8 to 10 investigators in a group. 0 nly eight perpetrators were interviewed by the Committee because 48 had already been interviewed in the Mistry $\&$ Dhlamini study referred to below.

3 In 2002 the CIAC undertook a study of house robberies in all nine provinces using docket analysis. The sample size was 1000 dockets.

4 Report of the Committee of Inquiry into Farm Attacks. p 351. July 2003. The sample size was 147 dockets for house robberies on farms and 66 dockets in urban areas. ' $O f$ those 77 had been disposed of in the manner described'.

5 D M istry \& J D hlamini. Perpetrators of Farm Attacks: An O ffender Profile. Institute for Human Rights and
Criminal Justice Studies. March 2001.

6 Interview with investigators, Limpopo and Free State.

7 The role of NOCOC in general is to deal with crime matters at an operational level. NOCOC is comprised of amongst others members of the SAPS headed by Deputy National Commissioner C A Pruis and SANDF.

8 At provincial level there is POCOC, area level $(\mathrm{AOCOC})$ and ground level $(\mathrm{GOCOC})$.

9 M Schonteich \& J Steinberg. Attacks on Farms and Smallholdings. An evaluation of the rural protection plan. 2000. Institute for Security Studies. p 20.

10 Ibid.

11 The marnet radio system is an area network communication system.

12 Schonteich \& Steinberg, op.cit p 21.

$13 \mathrm{lbid}$

14 Ibid.

15 The SANDF is responsible for co-ordinating the efforts of the Commandos.

16 Report of the Committee of Inquiry into Farm Attacks. July 2003.

17 Mistry \& Dhlamini. op.cit p 25. 